\title{
Unmet Supportive Care Needs among Breast Cancer Survivors of Community-Based Support Group in Kuching, Sarawak
}

\author{
Emmanuel Joseph Fong and Whye Lian Cheah \\ Department of Community Medicine \& Public Health, Faculty of Medicine \& Health Sciences, \\ Universiti Malaysia Sarawak, 94300 Kota Saramahan, Sarawak, Malaysia \\ Correspondence should be addressed to Whye Lian Cheah; wlcheah@unimas.my
}

Received 25 February 2016; Accepted 10 April 2016

Academic Editor: Debra A. Tonetti

Copyright (C) 2016 E. J. Fong and W. L. Cheah. This is an open access article distributed under the Creative Commons Attribution License, which permits unrestricted use, distribution, and reproduction in any medium, provided the original work is properly cited.

\begin{abstract}
Background. Recognizing the needs of cancer survivors is one of the important aspects in healthcare delivery. This study aimed to determine the prevalence of unmet supportive care needs and its associated factors among the breast cancer survivors of community-based support group in Kuching, Sarawak. Materials and Methods. This was a cross-sectional study using Supportive Care Needs Survey (SCNS-SF34). All the members of community-based breast cancer support groups in Kuching were invited. A total of 101 respondents were face-to-face interviewed after the consent was obtained. Data was entered and analyzed using SPSS version 20. Results. The respondents endorsed health system and information domain with the highest mean score (2.48; $95 \% \mathrm{CI}$ : 2.32-2.64). Top 10 items with "moderate to high" level unmet needs had a prevalence of $14.9 \%$ to $34.7 \%$ of respondents indicating need. Significantly higher level of unmet needs was associated with survivors who were younger (less than 60 years old), had higher education attainment, were unemployed, had survival duration of up to 5 years, and were undergoing active treatment. Conclusion. Systematic delivery of health information which is targeted, culturally sensitive, and linguistically appropriate for addressing younger age, education level, employment status, length of survivorship, and treatment stage should be considered not only at hospital-based setting but also at the community-based support groups.
\end{abstract}

\section{Introduction}

Breast cancer remains the most common cancer among women worldwide [1]. Similar experience is seen in Malaysia with breast cancer being the most common cancer among women [2]. Advances in detection and treatment modalities have improved the survival rate of women with breast cancer. In Malaysia, the 5-year survival rate among breast cancer patients has seen improvements over the past decades; studies revealed a 5-year observed survival from $58.4 \%$ (CI $0.54-$ 0.63 ) to $75.7 \%$ (CI $0.73-0.79$ ) [3]. Because of its high prevalence and relatively good prognosis, the increase in numbers of survivors forms a growing area of clinical interests and research.

A diagnosis of cancer can alter a person's perspective on health and life itself [4]. Female breast cancer survivors are often weighed down by issues of physical lethargy, pain, breast sensitivity, and difficulty to concentrate which were associated with diminished physical functioning and emotional well-being [5]. Their psychological well-being was found to be affected by fear of cancer spread, recurrence, distress from surgery, fear of second cancer, and future tests [6].

Cancer survivors face a wide range of problems during and after their primary treatment which often persists in a chronic, long-term manner [5]. During this period of survivorship, these survivors have multitude of needs which require attention and identification. Recognizing these needs early in the cancer care continuum is important. Therefore, needs assessment should be carried out as it offers three advantages: (i) patient's perceived needs are directly assessed, (ii) the level of need can be identified as well, and (iii) individuals or patient subgroups with higher level of needs can be identified [7]. Furthermore, understanding unmet needs among cancer survivors, across different age groups, gender, regions, cancer types, stages, survival durations, and 
various other factors, is in line with making healthcare patient-centered.

With the growing number of breast cancer survivors in the milieu of limited healthcare resources, there is a pressing demand to uncover the unmet needs of these survivors so that health systems may prioritize its service delivery in order to be more effective and efficient. Therefore, this study aims to describe the prevalence of unmet needs among breast cancer survivors in Kuching, Sarawak, and to assess relationship between their unmet needs and various associated factors.

\section{Materials and Methods}

This descriptive cross-sectional study was conducted among breast cancer survivors recruited from the communitybased nongovernmental organization (NGO) Sarawak Breast Cancer Support Group (SBCSG) in Kuching, Sarawak. Prior permission was obtained from the center in writing and all survivors in the support group were invited to participate in the study. Written informed consent was obtained prior to the interview assisted survey, which was conducted at the center from January 2014 to June 2014. This community-based approach, in which respondents were recruited, ensured that breast cancer survivors, whether they received treatment from public, private, or mixture of health facilities, were captured in this study.

The Supportive Care Framework by Fitch [8] recognizes that about $20 \%$ of cancer patients within the healthcare system have unmet needs. Recent studies showed that cancer patients in Taiwan and Hong Kong had prevalence of supportive care needs between $17-33 \%$ and $18-46 \%$, respectively [9]. Therefore, in order to estimate the $20 \%$ prevalence of unmet supportive care needs (moderate to high needs) with a confidence interval of $95 \%$ and a $10 \%$ margin of error, an estimate sample size of 62 was required as per the equation of $n=z^{2} p q / d^{2}$, where $z=1.96, p=0.2, q=1-p$, and $d=0.1[10]$. The eligibility criteria for inclusion in the study were (i) adult Malaysian females aged 18 years and above, (ii) diagnosed with breast cancer (all stages), and (iii) physically and mentally able to participate.

Sociodemographic characteristics of respondents such as age, ethnicity, marital status, cohabitation status, household income, education, and employment status were included in the survey. Medical characteristics such as age at diagnosis, duration of survivorship, cancer stage at time of diagnosis, and current treatment status were collected as well. The 34item short-form Supportive Care Needs Survey (SCNS-SF34) was adapted and employed in this study to identify the unmet supportive care needs among survivors [11]. Respondents have reported their preference for the SCNS questionnaire over other health-related quality of life questionnaires [12]. Furthermore, the SCNS-SF34 maintained the same constructs which were (i) psychological, (ii) physical and daily living, (iii) sexuality, (iv) health system and information, and (v) patient care and support, while preserving the psychometric properties of the original long-form SCNS [11]. Validation studies have shown that the Cronbach's alpha of the English version was 0.86-0.96 [11].
The 34-item Supportive Care Needs Survey (SCNS-SF34) offered an assessment of needs in cancer patients via five analytically derived domains: (i) psychological (10 items), (ii) physical and daily living (5 items), (iii) sexuality (3 items), (iv) health system and information (11 items), and (v) patient care and support (5 items). For each item, the respondents were required to indicate their level of need for help over the past one month in relation to having cancer. The level of need would be scored on a five-point Likert scale: 1 , no need, not applicable; 2 , no need, satisfied; 3 , low need; 4 , moderate need; and 5, high need. For each item, the respondents are dichotomized to as having "moderate to high" level of need if they scored options 4 or 5 or "no to low" level of need if they scored options 1, 2, or 3. The items with highest percentage of respondents reporting "moderate to high" level of need are then ranked and compared. The domain score was obtained by summing up the responses to each of the items within the domain and dividing the sum by the number of items in the domain. A higher mean score would indicate higher perceived need. For the purpose of analysis, the sociodemographic and medical characteristics of respondents were organized and compared with the supportive care needs domain mean scores using independent $t$-test and oneway analysis of variance (ANOVA). The collected data was then entered and analyzed using the IBM Statistical Product and Service Solutions (SPSS) statistics program version 20. Inferential statistics were generated to answer the study objective based on $p$ value of less than $0.05(p<0.05)$.

This study was conducted with approval from the Medical Ethics Committee, Faculty of Medicine and Health Science, Universiti Malaysia Sarawak (UNIMAS), Malaysia [UNIMAS/TNC(AA)-03.02/06-11 Jld. 3(12)].

\section{Results}

A total of 101 female breast cancer survivors participated in this study. The average age of respondents was 57.9 (SD 9.53) years. Majority of them were married $(79.2 \%)$ and Chinese (74.3\%). More than half of them were Christians (53.5\%). Most of the respondents stay with 2 to 4 other persons at home (56.4\%) and have an average household income of between RM 3001 to RM 5000 (43.6\%). Approximately 80\% of the respondents had primary and secondary school level education. Majority of the respondents were unemployed (70.3\%) which include survivors who were housewives and retired from employment.

The mean age at first diagnosis of breast cancer among the respondents in this study was 49.7 (SD 8.45) years with $54.5 \%$ of the respondents diagnosed at the age 50 years and older. Mean duration of survivorship was 8.2 (SD 5.72) years. Nearly two-thirds (63.4\%) of the respondents had a survival duration of more than 5 years. Approximately $80 \%$ of the respondents had early stage (Stages I and II) breast cancer at time of diagnosis. Among the respondents, $72.3 \%$ were no longer undergoing any active treatment at time of study and were only on annual outpatient department follow-ups. The other information on the sociodemographic and medical characteristics of the respondents is depicted in Table 1. 
TABLE 1: Sociodemographic and medical characteristics of respondents $(N=101)$.

\begin{tabular}{|c|c|c|c|}
\hline Sociodemographic and medical characteristics & $n$ & $\%$ & Mean (SD) \\
\hline Age (years) & & & $57.9(9.53)$ \\
\hline Below 60 & 57 & 56.4 & \\
\hline 60 and above & 44 & 43.6 & \\
\hline \multicolumn{4}{|l|}{ Ethnicity } \\
\hline Chinese & 75 & 74.3 & \\
\hline Malays and Sarawak indigenous group & 26 & 25.7 & \\
\hline \multicolumn{4}{|l|}{ Religion } \\
\hline Christianity & 54 & 53.5 & \\
\hline Buddhism & 25 & 24.8 & \\
\hline Islam & 20 & 19.8 & \\
\hline No religion & 2 & 2.0 & \\
\hline \multicolumn{4}{|l|}{ Marital status } \\
\hline Married & 80 & 79.2 & \\
\hline Never married/widowed/divorced/permanently separated & 21 & 20.8 & \\
\hline \multicolumn{4}{|l|}{ Cohabitation status } \\
\hline Lives alone or with 1 other person & 22 & 21.8 & \\
\hline Stays with 2 to 4 other persons & 57 & 56.4 & \\
\hline Stays with 5 or more other persons & 22 & 21.8 & \\
\hline \multicolumn{4}{|l|}{ Household income } \\
\hline Equal to or less than RM 3000 & 32 & 31.7 & \\
\hline RM 3001-5000 & 44 & 43.6 & \\
\hline More than RM 5000 & 25 & 24.8 & \\
\hline \multicolumn{4}{|l|}{ Formal education } \\
\hline Primary education & 20 & 19.8 & \\
\hline Secondary education & 61 & 60.4 & \\
\hline Postsecondary or tertiary education & 20 & 19.8 & \\
\hline \multicolumn{4}{|l|}{ Employment status } \\
\hline Unemployed $^{\mathrm{a}}$ & 71 & 70.3 & \\
\hline Employed $^{\mathrm{b}}$ & 30 & 29.7 & \\
\hline Age at diagnosis (years) & & & $49.7(8.45)$ \\
\hline Less than 50 & 46 & 45.5 & \\
\hline 50 and older & 55 & 54.5 & \\
\hline Duration of survivorship (years) & & & $8.2(5.72)$ \\
\hline Up to 5 & 37 & 36.6 & \\
\hline More than 5 & 64 & 63.4 & \\
\hline \multicolumn{4}{|l|}{ Cancer stage at time of diagnosis } \\
\hline Early stage (Stages I and II) & 79 & 80.6 & \\
\hline Later stage (Stages III and IV) & 19 & 19.4 & \\
\hline Do not know & 3 & 3.0 & \\
\hline \multicolumn{4}{|l|}{ Current treatment status } \\
\hline No current active treatment & 73 & 72.3 & \\
\hline Undergoing active treatment & 28 & 27.7 & \\
\hline
\end{tabular}

${ }^{\mathrm{a}}$ Unemployed: housewife/home maker, retiree.

${ }^{\mathrm{b}}$ Employed: government/private employee, self-employed.

Domain mean scores are identified by summing up the responses to each of the items within the domain and dividing the sum by the number of items in the domain. A higher score (maximum 5.00, minimum 1.00) would indicate higher level of needs in the domain. Table 2 revealed that health systems and information domain was found to have the highest mean score (2.48; 95\% CI, 2.32-2.64), followed by psychological domain (2.01; 95\% CI, 1.91-2.12) and patient care and support domain (1.93; 95\% CI, 1.83-2.03). Meanwhile, the sexuality domain has the lowest mean score $(1.57$; $95 \%$ CI, 1.44-1.70).

The top 10 items that respondents have indicated a "moderate to high" level of need for help are as depicted in 
TABLE 2: Domain mean score $(N=101)$.

\begin{tabular}{lccc}
\hline Rank & Domain & Mean (SD) & 95\% confidence interval for mean \\
\hline 1 & Health systems and information & $2.48(0.800)$ & $2.32-2.64$ \\
2 & Psychological & $2.01(0.534)$ & $1.91-2.12$ \\
3 & Patient care and support & $1.93(0.509)$ & $1.83-2.03$ \\
4 & Physical and daily living & $1.93(0.623)$ & $1.80-2.05$ \\
5 & Sexuality & $1.57(0.651)$ & $1.44-1.70$ \\
\hline
\end{tabular}

Table 3. Overall, 9 out of the top 10 items of unmet needs were from the health systems and information domain with only one item from the psychological domain. The highest ranked items were having one member of hospital staff with whom you can talk about all aspects of your condition, treatment, and follow-up (34.7\%), being given explanations on those tests about which you would like to get explanations (29.7\%), and having access to professional counseling (e.g., psychologist, social worker, counselor, and specialist nurse) if you, family, or friends need it $(27.7 \%)$.

The ten items with lowest "moderate to high" level unmet needs among the respondents are as shown in Table 4. Overall, the listed items had only less than $5 \%$ of the respondents indicated "moderate to high" level of need for help. Five out of 10 of these items are from the psychological domain, followed by sexuality domain (2 items), patient care and support domain (2 items), and physical and daily living domain $(1 \mathrm{item})$. Items with the lowest percentage of respondents reporting needs were feeling down or depressed (1\%), feelings of sadness (1\%), changes in sexual feelings (1\%), changes in your sexual relationships (1\%), and more choice about which hospital you attend (1\%).

The supportive care needs (SCNs) domain mean scores are compared to the sociodemographic and medical characteristics of the respondents in Table 5. Respondents age below 60 years $(n=57,56.4 \%)$ reported significantly higher mean score across physical and daily living domain $(p=0.009)$, psychological domain $(p=0.002)$, sexuality domain $(p<0.001)$, and patient care and support domain ( $p=0.038$ ) compared to survivors aged 60 years and older $(n=44,43.6 \%)$. Ethnic Malays and Sarawak indigenous group recorded higher mean score in the physical and daily living domain $(p=0.017)$ and sexuality domain $(p=$ 0.028 ) compared to the Chinese respondents. Survivors who are married reported higher mean score in the sexuality domain (1.69, 95\% CI: 1.54-1.84) compared to those who are never married/widowed/divorced/permanently separated (1.11, 95\% CI: 0.97-1.25) ( $p<0.001)$. Respondents with primary education level reported a significantly lower domain mean score compared to those with postsecondary or tertiary education level across the domains of physical and daily living (1.71 versus $2.19, p=0.012$ ), sexuality (1.33 versus 1.95, $p=0.007$ ), patient care and support (1.76 versus $2.21, p=$ 0.014 ), and health system and information (2.37 versus 3.00, $p=0.035)$. Respondents who were unemployed indicated a higher mean score in both the psychological domain (2.18 versus 1.94, $p=0.042$ ) and the patient care and support domain (2.13 versus $1.85, p=0.034$ ) compared to those who were still employed.
Meanwhile, when comparing the SCNs domain mean scores to the medical characteristics and disease stages of the respondents in Table 5, significantly higher mean scores were reported by respondents with survival duration of 5 years or less compared to those who have survived more than 5 years in the physical and daily living domain $(p<0.001)$, psychological domain $(p<0.001)$, sexuality domain $(p=$ $0.019)$, and patient care and support domain $(p=0.008)$. Treatment status among respondents showed significant difference in mean scores across all 5 domains with survivors undergoing active treatment indicating a higher mean score compared to those who are not undergoing any current active treatment ( $p$ value range from $<0.001$ to 0.019 ). There were no significant differences in supportive care needs domain mean scores among respondents with various cohabitation statuses, household income level, and age at diagnosis and between respondents who had early stage cancer compared to those with late stage cancer.

\section{Discussion}

The present study is a cross-sectional analysis of the perceived needs among breast cancer survivors in Kuching, Sarawak, Malaysia. The survivors recruited were generally less than 60 years old, were mainly Chinese, were married, received at least secondary level education, and were unemployed (Table 1).

The age at diagnosis (mean age 49.7) and staging (early stage, $80.6 \%$ ) were closely similar to various studies done in Malaysia [2]. The mean duration of survivorship which was 8.2 years and was higher in this study compared to 6.7 years in another local study [13]; this could be attributed to the fact that there were more later stage cases recruited from the hospital-based medical records in that study.

The current study (Table 2) revealed that survivors indicated a higher mean score (higher scores representing a higher level of unmet needs in the domain, range 1.00-5.00) in the health system and information domain $(2.48,95 \% \mathrm{CI}$ : 2.32-2.64), followed by psychological domain (2.01, 95\% CI: 1.91-2.12), and patient care and support domain (1.93, 95\% CI: 1.83-2.03). Meanwhile, sexuality domain was ranked lowest (1.57, 95\% CI: 1.44-1.70). This finding is consistent with recent research among breast cancer survivors in Singapore [14], Hong Kong [15], and Korea [16] which ranked the health system and information domain with the highest mean score. This tendency towards informational needs has been studied and established [17], with recent systematic reviews suggesting that Asian women reported higher informational needs 
TABLE 3: Top ten items with highest "moderate to high" unmet needs $(N=101)$.

\begin{tabular}{|c|c|c|c|}
\hline Rank & Item & $\%$ of respondents reporting needs & Domain \\
\hline 1 & $\begin{array}{l}\text { Having one member of hospital staff with } \\
\text { whom you can talk to about all aspects of } \\
\text { your condition, treatment, and follow-up }\end{array}$ & 34.7 & Health systems and information \\
\hline 2 & $\begin{array}{l}\text { Being given explanations on those tests } \\
\text { about which you would like to get } \\
\text { explanations }\end{array}$ & 29.7 & Health systems and information \\
\hline 3 & $\begin{array}{l}\text { Having access to professional counseling } \\
\text { (e.g., psychologist, social worker, } \\
\text { counselor, and specialist nurse) if you, } \\
\text { family, or friends need it }\end{array}$ & 27.7 & Health systems and information \\
\hline 4 & $\begin{array}{l}\text { Being adequately informed about the } \\
\text { benefits and side effects of treatments } \\
\text { before you choose to have them }\end{array}$ & 24.8 & Health systems and information \\
\hline 5 & $\begin{array}{l}\text { Being informed about your test results as } \\
\text { soon as feasible }\end{array}$ & 20.8 & Health systems and information \\
\hline 6 & $\begin{array}{l}\text { Being informed about cancer which is } \\
\text { under control or diminishing (i.e., } \\
\text { remission) }\end{array}$ & 20.8 & Health systems and information \\
\hline 7 & $\begin{array}{l}\text { Being given information (written } \\
\text { information, diagrams, and drawings) } \\
\text { about aspects of managing your illness } \\
\text { and side effects at home }\end{array}$ & 18.8 & Health systems and information \\
\hline 8 & Fears about the cancer spreading & 16.8 & Psychological \\
\hline 9 & $\begin{array}{l}\text { Being informed about things you can do } \\
\text { to help yourself to get well }\end{array}$ & 14.9 & Health systems and information \\
\hline 10 & $\begin{array}{l}\text { Being treated in a hospital or clinic that is } \\
\text { physically pleasant as possible }\end{array}$ & 14.9 & Health systems and information \\
\hline
\end{tabular}

TABle 4: Top ten items with lowest "moderate to high" unmet needs $(N=101)$.

\begin{tabular}{lrrr}
\hline Rank & Item & \% of respondents reporting needs & Domain \\
\hline 1 & Feeling down or depressed & 1.0 & Psychological \\
2 & Feelings of sadness & 1.0 & Psychological \\
3 & Changes in sexual feelings & 1.0 & Sexuality \\
4 & Changes in your sexual relationships & 1.0 & Sexuality \\
5 & More choices about which hospital you attend & 1.0 & Patient care and support \\
6 & Learning to feel in control of your situation & 2.0 & Psychological \\
7 & Keeping a positive outlook & 3.0 & Psychological \\
8 & Hospital staff attending promptly to your physical needs & 3.0 & Patient care and support \\
9 & Pain & 4.0 & Physical and daily living \\
10 & Worry that the results of treatment are beyond your control & 4.0 & Psychological \\
\hline
\end{tabular}

compared to Western women [18]. Furthermore, the current finding could suggest a dissatisfaction among survivors with information received during follow-up care [16].

Based on individual item ranking (Table 3), there is a greater need expressed within the health system and information domain compared to the other domains such as psychological domain. These findings however were in contrast to multiple Australian-based research outcomes, in which cancer survivors ranked the psychological domain as area with highest level unmet needs $[11,19]$. Such difference in prevalence has been established in recent systematic review [18] and could be a reflection of underlying cross-continental cultural difference between survivors of Asian compared to Australian origin.

Furthermore, needs among survivors are dynamic and may change over time. Researchers discovered a shift in perceived needs from informational needs to psychological needs among cancer survivors, citing improvements in information delivery over the years, which have led to the shift [20]. Assuming this trend holds true for cancer survivors worldwide, the current trend in this study indicates much needs to be done in addressing the informational needs of our survivors. Nevertheless, a less emphasis on psychological domain in this study sample could be influenced by the 


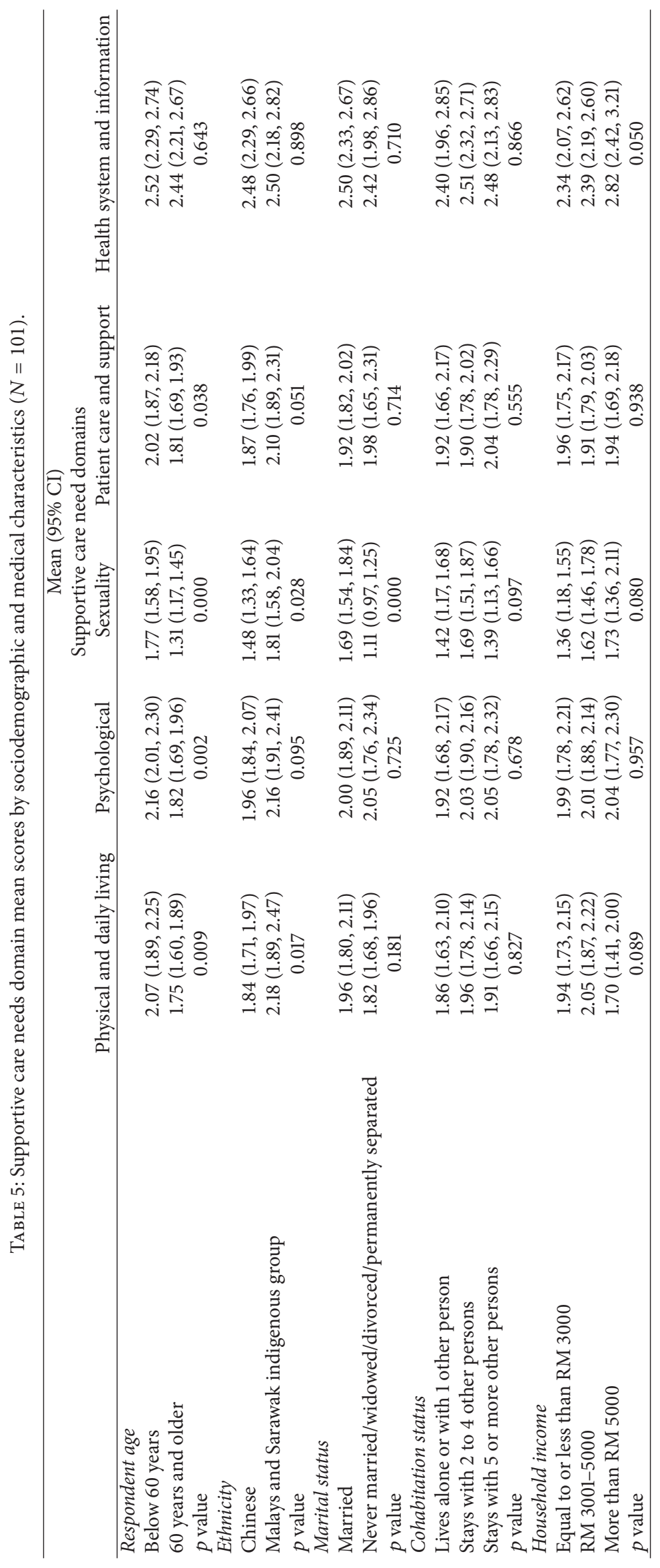


fact that the study population was from a community-based breast cancer support group, in which their psychological and emotional needs would probably have been addressed. This finding highlights the importance of proper support group among cancer survivors [21], as well as having breast cancer survivors as support members [12].

Younger respondents aged below 60 years old reported higher level of unmet needs across all 5 domains compared to their older counterparts (Table 5), with significant differences seen in the domains of sexuality, psychological, physical and daily living, and patient care and support. This observation is congruent with studies by researchers in Singapore, which demonstrated that the level of need is higher among survivors aged below 60 years [22]. Similarly Australian cancer patients aged 31-60 years endorsed higher levels of unmet needs in sexuality, psychological, patient care and support, and health system and information domains compared to those who are 70 years or older [20]. Comparable conclusions were drawn from a qualitative study which explored the psychosocial needs of breast cancer survivors in which younger women reported a higher level of needs in terms of support, psychological, practical, physical and information needs [23]. Such disparity may reflect the difference in attitudes between younger adults who are more vocal of their unmet needs than older adults who believe that they should have better coping capacity and thus keep things to themselves [20]. Additionally, a diagnosis of cancer in younger adults may impart a sense of perceived loss in all areas of life, such as physical, psychosocial, emotional, sexuality, and the need for support, which give rise to higher magnitude of needs compared to older adults who may well have adjusted to changes in their life as they age. There were, however, no significant differences $(p=0.643)$ in mean scores within the health system and information domain which may suggest that, across all age group, the informational need is ever present once a person is diagnosed with cancer.

Significant difference in mean domain scores was found between Malays and Sarawak indigenous groups compared to ethnic Chinese survivors in both the physical and daily living (2.18 versus $1.84, p=0.017$ ) and sexuality (1.81 versus $1.48, p=0.028)$ domains. This variation could be influenced by the fact that almost $75 \%$ of the respondents in this study were of ethnic Chinese group, and the number of Malays and Sarawak indigenous groups were inadequate to be representative. In the absence of adequate research information, this finding is inconclusive. There may be an element of cultural background and variation in health beliefs which influence the level of needs in these domains. Further exploration into this area is needed to understand these variations. Comparison with other studies involving ethnic Chinese survivors revealed similar lower scores in sexuality domain $[9,14]$ and physical and daily living domain [22]. Lower sexuality domain scores could be due to underreporting of sexuality needs, as it is regarded as an intimate matter and not for discussion within the Asian Chinese community. Specific cultural norms among the Chinese could also account for lower physical and daily living needs, as it is believed that personal problems or outcry for help reflects badly on the family and may bring shame to the family name [24]; therefore, this may lead to a lower report for need in this domain among the Chinesemajority sample of this study.

Higher level of unmet needs in the sexuality domain was endorsed by survivors who are married compared to others $(p<0.001)$. This was consistent with a Korean study [25] whereby married patients $(p=0.03)$ were significantly more likely to indicate the need for help in this domain. Furthermore, this finding makes intuitive sense, given that married survivors have spouse in whom they need to confront their sexuality needs more frequently, hence giving rise to needs.

Higher education attainment was associated with greater level of unmet needs among the respondents (Table 5) with mean domain scores being significantly different between respondents with primary level compared to postsecondary or tertiary level education in psychological, sexuality, patient care and support, and health system and information domains. This finding is in agreement with other studies which concluded that education level was found to be predictor of higher level of unmet needs among breast cancer survivors $[25,26]$. Survivors with higher level of education are more aware and receptive of their underlying conditions, this has led to their need to actively seek ways to improve their current state of health, and the barriers which they face would be reflected in the domain scores.

Current study revealed that survivors who were unemployed reported a higher domain mean score across all 5 domains compared to those who were employed (Table 5) with significant differences reported in the psychological and patient care and support domains. There may be underlying factors which influence this outcome. A survivor may be unemployed due to various reasons. Among them could be complications from treatment of breast cancer with residual deficits, which would hamper their ability to work and thus be reported as "unemployed." Such disadvantage may increase their needs in the psychological and patient care and support domain.

In this study, shorter duration of survivorship was significantly associated with higher domain mean score across all supportive care needs domains except the health system and information domain (Table 5). This is in agreement with recent systematic review which suggests shorter time since diagnosis predicts higher level of needs [18]. These findings can be attributed to the fact that newly diagnosed cancer patients had greater physical and emotional needs compared to those who were already receiving posttreatment follow-up care [27]. This universal observation illustrates the need for concerted effort at addressing unmet needs across various domains early in cancer survivorship. Furthermore, independent of survival duration, informational needs among current survivors are persistent throughout the continuum of survivorship care with no differences seen between younger or older survivors. This could be an indication highlighting the gap in information flow between providers and patients. Closing this gap, a systematic approach in information delivery across the period of survivorship with focus on different aspect of needs and its change in relation to survival duration is needed. 
Being under active treatment is significantly associated with higher mean scores across all 5 domains in this study ( $p$ value range $<0.001$ to 0.019 ) (Table 5 ). This finding is consistent with other studies whereby patients under treatment reported high level of unmet needs [28] while those in remission reported fewer unmet needs in the psychological, information, daily living, and patient care domains [20]. Additionally, recent findings among breast cancer survivors showed that those who were not in remission were associated with unmet needs in health system and information and patient care and support domains suggesting that these groups of survivors are likely to be receiving intermittent treatment and had to deal with symptom management [19]. Greatest difference in mean scores was observed in the physical and daily living domain (2.33 versus 1.77, $p<0.001$ ). This difference can be attributed to the fact that survivors receiving active treatment were still coping with physical side effects of treatment modalities such as surgery and chemotherapy and hence had much greater need in this domain compared to those who were not on any active treatment any more.

There was no significant difference in mean scores across all 5 domains in relation to cohabitation status of the survivors $(p=0.097-0.866)$ (Table 5). This finding is different from other studies which concluded that generally cancer survivors living alone reported higher level of unmet needs [29], and breast cancer survivors living alone reported significantly more needs in area of patient care domain $(p=$ 0.044) [25]. This could be influenced by the fact that the sampled survivors were recruited from a community-based breast cancer support group, and these survivors being part of this group have had some of their needs satisfied. This could lead to a less obvious discrepancy among the samples.

Household income level did not show any significant difference in any of the 5 domains mean scores. This finding differs from a Korean study which concluded that less income predicted higher needs in physical and daily living domain $(p=0.019)$ [25]. It was suggested that having less income leads to financial barriers in terms of ability to satisfy daily personal care and physical needs [25]. Majority of these survivors receive their initial management and follow-up care from the public funded government health facilities which are considered to be relatively free, and therefore the income level within the current healthcare system does not make much impact.

Current study revealed that, in relation to cancer stage at time of diagnosis, there was no significant difference in mean scores across all domains ( $p$ value range 0.627 to 0.964 ). This however was different from other studies which reported that tumor size was significant in predicting needs in the psychological and health system and information domains [25]. Nevertheless, this study suggests that, independent of cancer staging at time of diagnosis, there are still unmet needs to be addressed, with highest mean score in the health system and information domain, Early stage (2.48, 95\% CI: 2.30-2.66) and later stage (2.42, 95\% CI: 1.98-2.85). The present finding may highlight a lack of understanding among survivors about the differences of cancer staging which also is indirectly reflected in the high level of unmet needs in the health system and information domain. On the other hand, there may be some form of underlying passive coping mechanism in play, whereby survivors choose to keep themselves occupied and not to think too much about their condition [25]; therefore the differences in staging (early or later state) do not weigh in on their unmet needs mean scores.

The present study has several limitations. First, it was conducted among survivors in a community-based support group, whereby participation was based on voluntary basis and representation from late stage (Stages III and IV), that survivors may be less than expected. This could be attributed to the fact that late stage survivors have shorter life span and might not be in the best health to participate regularly in support group activities. Second, the Chinese-majority ethnic representation in this study, despite not being the majority population in the country, concurs with other local studies and characterizes the higher breast cancer incidence rate among the Chinese in Malaysia. Third, the inherent limitation of being a cross-sectional study means that causeeffect relationships could not be assessed, and changes in unmet needs could not be evaluated over time. Despites these limitations, this study has its strength in the fact that samples were drawn from community-dwelling breast cancer survivors which is more likely to represent their needs in the actual lived-in environment compared to samples obtained purely from hospitals.

In conclusion, this study provided valuable insights into the characteristics of breast cancer survivors in Kuching, Sarawak, and their associated unmet supportive care needs with gaps in the informational domain emphasized. Efforts should include the systematic delivery of health information which is targeted, culturally sensitive, and linguistically appropriate, especially to breast cancer survivors who were younger, had higher education attainment, were unemployed, had survivorship of 5 years or less, and were undergoing active treatment. Future research should recruit samples from both community-based support group and survivors receiving treatment. A longitudinal exploration of the supportive care needs relative to survival duration is also recommended.

\section{Competing Interests}

The authors declared that they have no competing interests.

\section{Acknowledgments}

The authors would like to thank the Director General of Health, Malaysia, for the permission to publish this paper.

\section{References}

[1] F. Bray, J.-S. Ren, E. Masuyer, and J. Ferlay, "Global estimates of cancer prevalence for 27 sites in the adult population in 2008," International Journal of Cancer, vol. 132, no. 5, pp. 1133-1145, 2013.

[2] C. H. Yip, N. A. M. Taib, and I. Mohamed, "Epidemiology of breast cancer in Malaysia," Asian Pacific Journal of Cancer Prevention, vol. 7, no. 3, pp. 369-374, 2006.

[3] N. A. Taib, M. N. Akmal, I. Mohamed, and C.-H. Yip, "Improvement in survival of breast cancer patients-trends in survival 
over two time periods in a single institution in an Asia Pacific country, Malaysia," Asian Pacific Journal of Cancer Prevention, vol. 12, no. 2, pp. 345-349, 2011.

[4] M. L. Vachon, "The meaning of illness to a long-term survivor," Seminars in Oncology Nursing, vol. 17, no. 4, pp. 279-283, 2001.

[5] P. A. Ganz, L. Kwan, A. L. Stanton et al., "Quality of life at the end of primary treatment of breast cancer: first results from the moving beyond cancer randomized trial," Journal of the National Cancer Institute, vol. 96, no. 5, pp. 376-387, 2004.

[6] B. R. Ferrell, M. Grant, B. Funk, N. Garcia, S. Otis-Green, and M. L. J. Schaffner, "Quality of life in breast cancer," Cancer Practice, vol. 4, no. 6, pp. 331-340, 1996.

[7] B. Bonevski, R. Sanson-Fisher, A. Girgis, L. Burton, P. Cook, and A. Boyes, "Evaluation of an instrument to assess the needs of patients with cancer. Supportive Care Review Group," Cancer, vol. 88, no. 1, pp. 217-225, 2000.

[8] M. Fitch, "Supportive care framework," Canadian Oncology Nursing Journal, vol. 18, no. 1, pp. 6-24, 2008.

[9] R. Fielding, W. W. Lam, S. C. Shun et al., "Attributing variance in supportive care needs during cancer: culture-service, and individual differences, before clinical factors," PLOS ONE, vol. 8, no. 5, Article ID e65099, 2013.

[10] W. W. Daniel, Biostatistics: A Foundation for Analysis in the Health Sciences, John Wiley \& Sons, Hoboken, NJ, USA, 2005.

[11] A. Boyes, A. Girgis, and C. Lecathelinais, "Brief assessment of adult cancer patients' perceived needs: development and validation of the 34-item supportive care needs survey (SCNSSF34)," Journal of Evaluation in Clinical Practice, vol. 15, no. 4, pp. 602-606, 2009.

[12] H. Caulton, "Support groups whose members have themselves had breast cancer are helpful," British Medical Journal, vol. 313, no. 7053, pp. 361-362, 1996.

[13] R. A. M. Al-Naggar, Z. Md Isa, S. A. Shah et al., "Eight year survival among breast cancer Malaysian women from University Kebangsaan Malaysia Medical Centre," Asian Pacific Journal of Cancer Prevention, vol. 10, no. 6, pp. 1075-1078, 2009.

[14] K. K. F. Cheng, R. D. Devi, W. H. Wong, and C. Koh, "Perceived symptoms and the supportive care needs of breast cancer survivors six months to five years post-treatment period," European Journal of Oncology Nursing, vol. 18, no. 1, pp. 3-9, 2014.

[15] A. Au, W. Lam, J. Tsang et al., "Supportive care needs in Hong Kong Chinese women confronting advanced breast cancer," Psycho-Oncology, vol. 22, no. 5, pp. 1144-1151, 2013.

[16] B. W. Park and S. Y. Hwang, "Unmet needs of breast cancer patients relative to survival duration," Yonsei Medical Journal, vol. 53, no. 1, pp. 118-125, 2012.

[17] C. Kwok and K. White, "Perceived information needs and social support of Chinese-Australian breast cancer survivors," Supportive Care in Cancer, vol. 22, no. 10, pp. 2651-2659, 2014.

[18] C. Fiszer, S. Dolbeault, S. Sultan, and A. Brédart, "Prevalence, intensity, and predictors of the supportive care needs of women diagnosed with breast cancer: a systematic review," PsychoOncology, vol. 23, no. 4, pp. 361-374, 2014.

[19] A. W. Boyes, A. Girgis, C. D'este, and A. C. Zucca, "Prevalence and correlates of cancer survivors' supportive care needs 6 months after diagnosis: a population-based cross-sectional study," BMC Cancer, vol. 12, article150, 2012.

[20] R. Sanson-Fisher, A. Girgis, A. Boyes, B. Bonevski, L. Burton, and P. Cook, "The unmet supportive care needs of patients with cancer. Supportive Care Review Group," Cancer, vol. 88, no. 1, pp. 226-237, 2000.
[21] B. A. Matthews, F. Baker, and R. L. Spillers, "Oncology professionals and patient requests for cancer support services," Supportive Care in Cancer, vol. 12, no. 10, pp. 731-738, 2004.

[22] R. Ng, H. M. Verkooijen, L. L. Ooi, and W.-P. Koh, "Unmet psychosocial needs among cancer patients undergoing ambulatory care in Singapore," Supportive Care in Cancer, vol. 20, no. 5, pp. 1049-1056, 2012.

[23] B. Thewes, P. Butow, A. Girgis, and S. Pendlebury, "The psychosocial needs of breast cancer survivors; a qualitative study of the shared and unique needs of younger versus older survivors," Psycho-Oncology, vol. 13, no. 3, pp. 177-189, 2004.

[24] L. A. Mclaughlin and K. L. Braun, "Asian and Pacific Islander cultural values: considerations for health care decision making," Health \& Social Work, vol. 23, pp. 116-126, 1998.

[25] S. Y. Hwang and B.-W. Park, "The perceived care needs of breast cancer patients in Korea," Yonsei Medical Journal, vol. 47, no. 4, pp. 524-533, 2006.

[26] M.-N. Liao, S.-C. Chen, S.-C. Chen et al., "Changes and predictors of unmet supportive care needs in taiwanese women with newly diagnosed breast cancer," Oncology Nursing Forum, vol. 39, no. 5, pp. E380-E389, 2012.

[27] T. J. Whelan, E. A. Mohide, A. R. Willan et al., "The supportive care needs of newly diagnosed cancer patients attending a regional cancer center," Cancer, vol. 80, no. 8, pp. 1518-1524, 1997.

[28] J. D. Harrison, J. M. Young, M. A. Price, P. N. Butow, and M. J. Solomon, "What are the unmet supportive care needs of people with cancer? A systematic review," Supportive Care in Cancer, vol. 17, no. 8, pp. 1117-1128, 2009.

[29] A. G. Veloso, C. Sperling, L. V. Holm et al., "Unmet needs in cancer rehabilitation during the early cancer trajectory-a nationwide patient survey," Acta Oncologica, vol. 52, no. 2, pp. 372-381, 2013. 


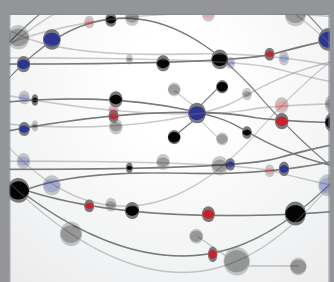

The Scientific World Journal
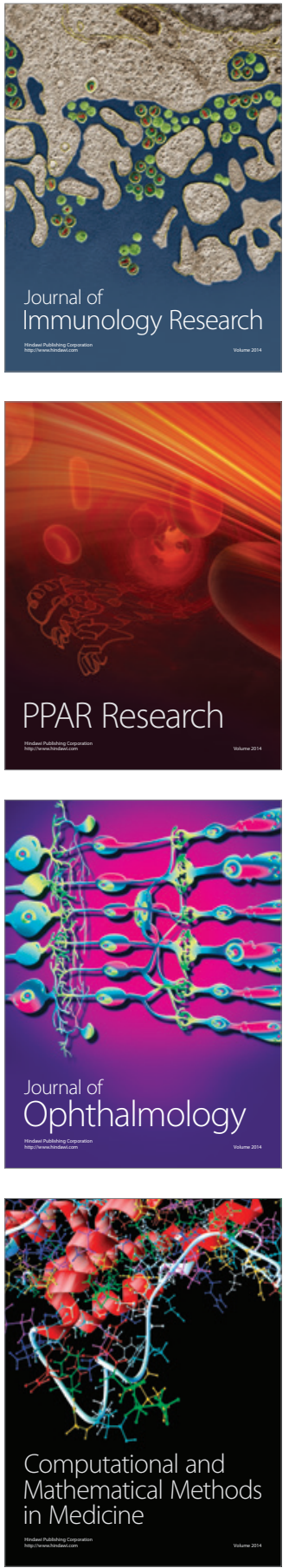

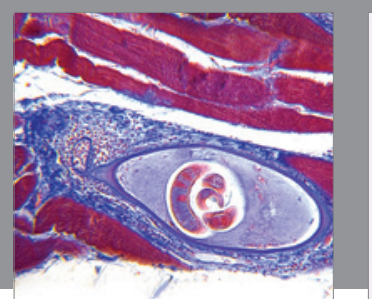

Gastroenterology Research and Practice

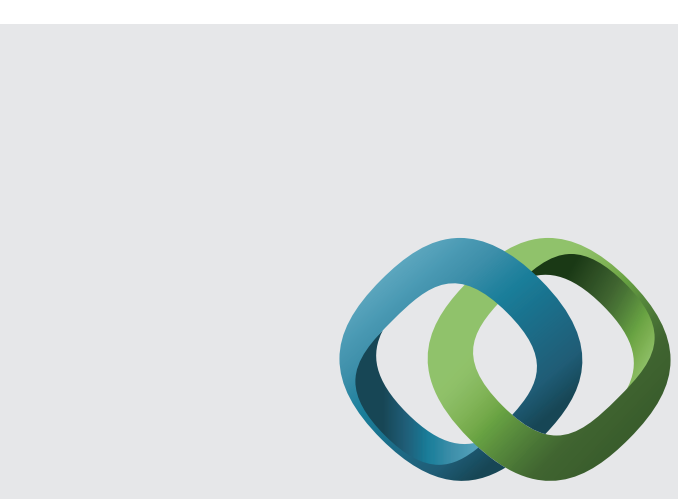

\section{Hindawi}

Submit your manuscripts at

http://www.hindawi.com
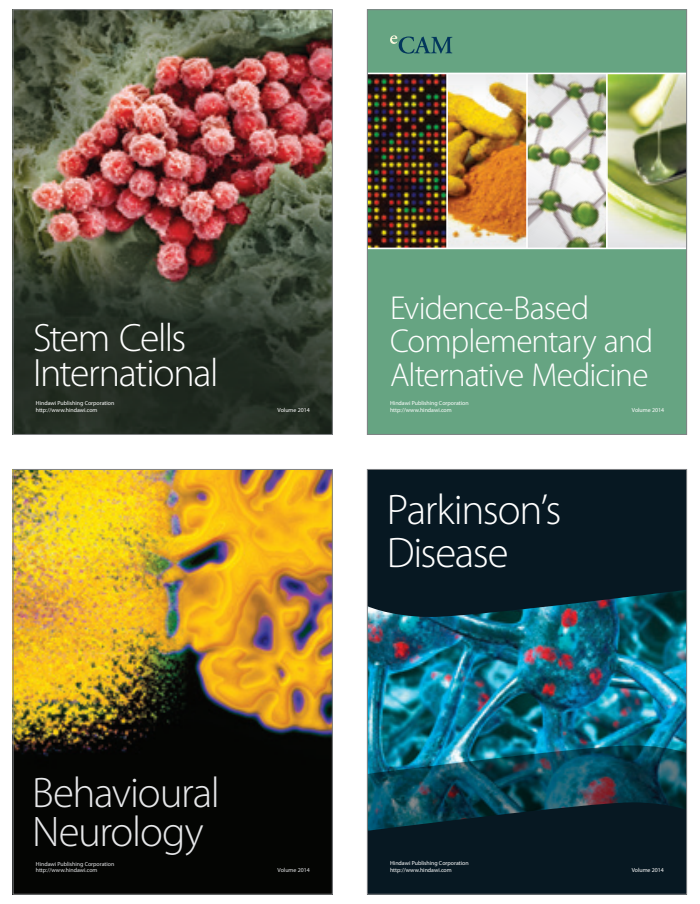
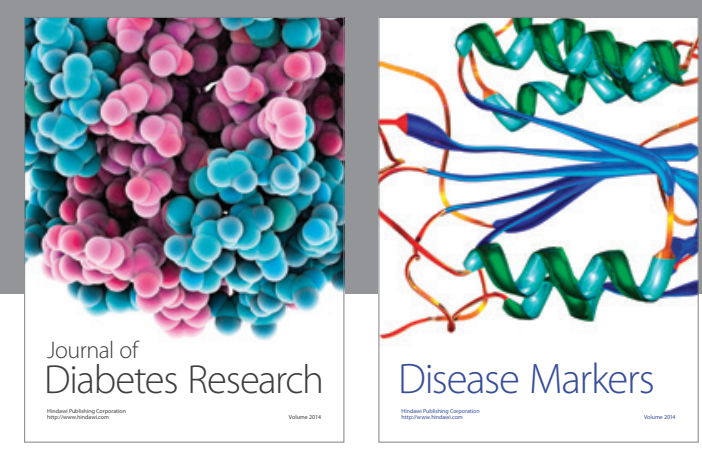

Disease Markers
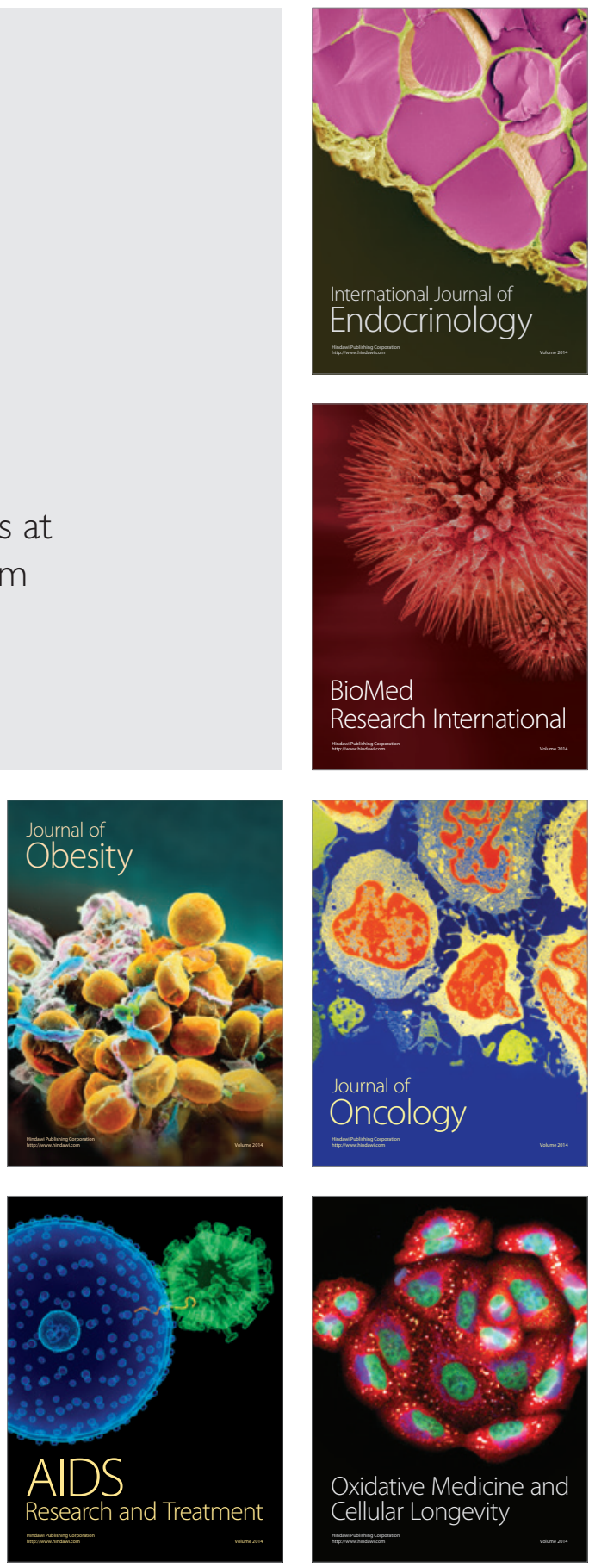